\title{
Production of Safe Charcoal from Waste Construction Wood Treated With Citric Acid
}

\author{
Masafumi Tateda', Masaru Okura', Youngchul Kim², Bandunee Champika Liyanage Athapattu ${ }^{3}$ \\ ${ }^{1}$ Department of Environmental Engineering, Toyama Prefectural University, Imizu, Japan; ${ }^{2}$ Department of Environmental Engineer- \\ ing, Hanseo University, Seosan-si, Korea; ${ }^{3}$ Department of Civil Engineering, The Open University of Sri Lanka, Nawala, Sri Lanka. \\ Email: tateda@pu-toyama.ac.jp
}

Received August 6 $6^{\text {th }}, 2011$; revised September 12 ${ }^{\text {th }}, 2011$; accepted October $13^{\text {th }}, 2011$.

\begin{abstract}
For practical reuse of wastewater containing citric acid and the production of safe and healthy high-quality charcoal from waste construction wood, basic data regarding the influence of citric acid washing treatments on the physicochemical property of charcoal was investigated in order to find the benefits of using citric acid for washing out impurities of the wood, owing to its chelate bonding ability with elements such as metals. Parameters obtained for evaluating the benefits were water content, volatile component content, ash content, fixed carbon content, and the heat value of the charcoal. All parameters, except ash content, throughout all carbonization temperatures were not significantly different between the charcoal of the wood treated with and without citric acid. However, the ash content showed significant differences between the charcoal treated with and without citric acid throughout all carbonization temperatures. Regarding the heat value, the highest heat value was shown on the charcoal carbonated at $600^{\circ} \mathrm{C}$ with the static washing treatment. Dioxins that were higher in content than the control sample were somehow detected in the ash of the charcoal with the shaking treatment. Further investigation is needed for the production of safe and healthy charcoal using waste citric acid.
\end{abstract}

Keywords: Charcoal, Waste Construction Wood, Citric Acid, Metals, Ash, Dioxins

\section{Introduction}

Generation of construction waste in Japan was approximately 64 million tons in 2008, which is a drastic decrease from 77 million tons in 2005. The amount of final disposal to landfill sites also decreased from 6 to 4 million tons in 2005 and 2008, respectively. This large reduction was mainly related to a significant decrease in the number of construction contracts, owing to the Japanese economic depression and severe cut-off of public construction works ordered by the central or local governments. Construction waste in 2005 consists of waste concrete (42\%), waste asphalt and concrete (34\%), construction sludge $(10 \%)$, waste construction wood $(6 \%)$, mixed construction waste $(4 \%)$, and others $(4 \%)$. The difference reported for 2008 was not a large one [1]. While more than $97 \%$ of waste concrete or waste asphalt and concrete were recycled, waste construction wood was about $80 \%$. The Recycling ratio of waste construction wood is not as high as the ratios of waste concrete and waste asphalt and concrete. Waste construction wood is currently recycled for energy recovery by heat after being chopped, production of woody board as a construction material, a raw material for paper production, and composting; however, demand for these recycled products is very low. In the near future, houses constructed in the 1960's will be demolished because of lifetime expiration. Therefore, a large amount of waste construction wood is expected to be generated; hence, it is desired to find ways for recycling that can produce more products demanded by markets. On the other hand, citric acid wastewater including sucrose and vitamin $\mathrm{C}$ is generated from food processing factories such as canned fruit processing factories. Treatment of the wastewater presents a high cost to factories. The ingredients in wastewater are not toxic materials such as heavy metals and persistent organic compounds but rather a kind of resource, so they can be and should be used as substrates for some biological processes such as composting. However, it could be more beneficial if there are more options to use ingredients before moving on to composting. It is already widely known that citric acid has an ability to purify materials contaminated by elements such as cations because the acid removes cations such as $\mathrm{Cd}$ and 
$\mathrm{Pb}$ by its chelate bonds with the elements. The objective of this study was to find benefits of citric acid washing of waste construction wood. Charcoal was produced from waste construction wood by carbonization after washing with citric acid. Characteristics of the charcoal were investigated and compared with charcoal that was normally produced. The washing and purification ability of citric acid was the focus of this study and applied to waste construction wood in order to produce high-quality charcoal.

\section{Materials and Methods}

\subsection{Waste Construction Wood}

Waste construction wood was obtained from a waste management company in Imizu City, Toyama, Japan. Water content of the wood was 16\%, and it is shown in Figure 1.

\subsection{Chemical}

Commercial citric acid (Special grade, Kanto Chemical, Japan) was used for the washing process.

\subsection{Experimental Methods}

1) Washing waste construction wood with citric acid in static condition

A citric acid solution (5\%) was prepared, and a mixture of wood and citric acid with a ratio of $200 \mathrm{~g}: 2000 \mathrm{ml}$ (1:10) was mixed in a plastic basket. The wood was put into a net bag in order to prevent dispersion in the solution. Another plastic basket full of water was placed on the wood in the net in order to make the wood completely sink in the citric solution and it was left for $24 \mathrm{~h}$. After $24 \mathrm{~h}$, the wood was removed from the basket and dried at $105^{\circ} \mathrm{C}$ for $24 \mathrm{~h}$.

2) Washing waste construction wood by citric acid in shaking condition

A citric acid solution (5\%) was prepared, and a mixture of wood and citric acid with a ratio of $50 \mathrm{~g}: 500 \mathrm{ml}$ (1:10) was mixed in a $1000 \mathrm{ml}$ plastic container. The cap of the container was tightly closed and shaken at 150

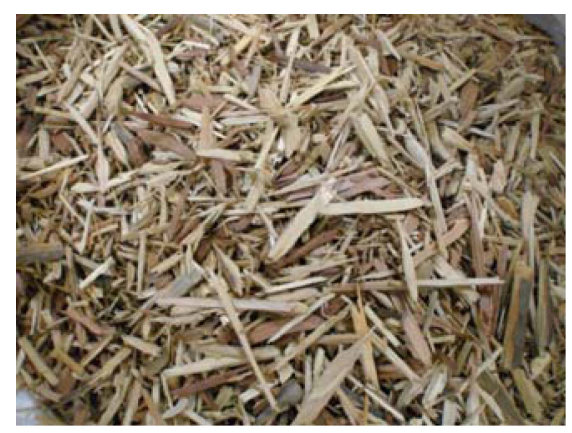

Figure 1. Waste Construction Wood. rpm and at room temperature for $24 \mathrm{~h}$ in a rotary shaker (OSI-501LD, EYELA). After $24 \mathrm{~h}$, the wood was removed from the basket and dried at $105^{\circ} \mathrm{C}$ for $24 \mathrm{~h}$.

3) Measurement of $\mathrm{COD}_{\mathrm{Mn}}$ and analysis of impurities extracted in citric acid solution after washing

After static and shaken washing, the citric acid solution was filtered with a cellulose acetate $0.80 \mu \mathrm{m}$ filter (ADVANTEC). $\mathrm{COD}_{\mathrm{Mn}}$ of the solution was measured following the procedure of JIS K 0102 (Japanese Industrial Standard). A qualitative analysis of the extracted elements from waste construction wood in the solution was also performed with an ICP emission spectrophotometer (Optima 5300 DV-TK, PerkinElmer).

4) Carbonization and its condition

Fourteen grams of waste construction wood was placed into a crucible (B3 type) and the crucible was closed with a lid; it was then placed in an electric furnace (KBF784N1, KOYO Thermosystem). Carbonization temperatures were selected from $300^{\circ} \mathrm{C}$ to $1100^{\circ} \mathrm{C}$ with a $100^{\circ} \mathrm{C}$ interval; the waste construction wood was held at each temperature for $1 \mathrm{~h}$. After the sample was cooled, it was removed from the furnace.

5) Charcoal property analysis

The charcoal produced in section 2.3.4) was powdered to less than $250 \mu \mathrm{m}$ with a planetary ball mill (Pulverisette 7, Fritsch). The powdered sample was spread out and dried at room temperature. The water, ash, and volatile component content of the sample were measured following the procedure of JIS M 8812. Fixed carbon content was calculated using values of the water, ash, and volatile component content. The heat value was also obtained. Details have been described in the following sections. All measurements were triplicate $(\mathrm{p}<0.05)$.

a) Water content

One gram of the dried sample was placed into a weighing sampler (Cylinder $40 \times 60 \mathrm{~mm}$ ) and the sample was dried at $107^{\circ} \mathrm{C}$ for $1 \mathrm{~h}$ in a thermostatic dryer (MOV212U, Sanyo). After cooling in a desiccator, the sample was measured for its water content by weight difference between before and after drying.

b) Ash content

One gram of the dried sample was placed in a crucible (B0 type), and the sample was placed in an electric furnace (KBF794N1, KOYO Thermosystem). The inside temperature of the furnace gradually increased to $500^{\circ} \mathrm{C}$, taking $60 \mathrm{~min}$, and next to $815^{\circ} \mathrm{C}$, taking another $45 \mathrm{~min}$, then held at temperature for $1 \mathrm{~h}$. After cooling in a desiccator, the sample was measured for its ash content by weight difference between before and after of combustion.

c) Volatile component content

One gram of the dried sample was placed in a crucible (B0 type), and the crucible was closed with a lid. The 
sample was combusted at $900^{\circ} \mathrm{C}$ for $7 \mathrm{~min}$ in an electric furnace (KBF794N1, KOYO Thermosystem) and cooled in a desiccator. The percentage of weight difference between before and after combustion was first obtained and the percentage was subtracted from the water content, and then the remaining percentage became the volatile component content of the sample.

d) Fixed carbon content

The following equation was used to obtain fixed carbon content:

Fixed carbon content $(\%)=100-[$ Water content $(\%)$

+ Ash content (\%) + Volatile component content (\%)].

e) Heat value

Heat values of the dried prepared samples were obtained by a bomb calorimeter (1013-B, Yoshida) following JIS M 8814.

6) SEM and EDS observations

SEM observations of the charcoal produced at $300^{\circ} \mathrm{C}$, $400^{\circ} \mathrm{C}, 600^{\circ} \mathrm{C}, 700^{\circ} \mathrm{C}$, and $1000^{\circ} \mathrm{C}$ carbonation temperatures in section 2.3.4) were performed using a scanning electron microscope (SSX-550, Shimadzu). Magnification was chosen at $\times 3000$. EDS observation was also conducted on the charcoal carbonized at $1000^{\circ} \mathrm{C}$ in section 2.3.4) using an energy dispersive $\mathrm{X}$-ray spectrometer attached to the scanning electron microscope (SSX-550, Shimadzu). A fundamental parameter (FP) was used for quantitative calculation.

7) Analysis of dioxins

One gram of the charcoal samples, both with and without citric acid washing, and using only the shaken washing method was chosen. The samples carbonized at $600^{\circ} \mathrm{C}$ in section 2.3.4), were placed in a crucible (B0 type) and combusted at $500^{\circ} \mathrm{C}$ for $1 \mathrm{~h}$ in an electric furnace (KBF794N1, KOYO Thermosystem). Quantitative analysis of the dioxins found in the combustion ash was performed by analysis using a gas chromatograph mass spectrometer (Waters/MICROMASS). The samples that added $0.3 \mathrm{ml}$ of oil and $0.04 \mathrm{~g}$ of salt per gram of charcoal were also prepared and combusted under the same condition as normal samples in order to see any acceleration of dioxin formation with the existence of the oil and salt. We assumed that $100 \mathrm{ml}$ oil and $10 \mathrm{~g}$ salt per $1 \mathrm{~kg}$ of charcoal was reasonable amount fallen on the surface on a charcoal when grilled meats on a stick or in barbecue were served, and just multiplied the amounts 3 - 4 times for expecting more dioxin formation.

\section{Results}

\subsection{Results of $\mathrm{COD}_{\mathrm{Mn}}$ and Analysis of Impurities Extracted from Citric Acid solution after Washing}

$\mathrm{COD}_{\mathrm{Mn}} \mathrm{S}$ in the citric acid solution after washing waste construction wood under different washing methods are shown in Figure 2. The $\mathrm{COD}_{\mathrm{Mn}} \mathrm{S}$ of citric acid solutions (29000 mg/l) after washing were larger than the control sample $(28000 \mathrm{mg} / \mathrm{l})$. It showed that some organic matter was extracted from waste construction wood by citric acid, and the same increase $(1000 \mathrm{mg} / \mathrm{l})$ in $\mathrm{COD}_{\mathrm{Mn}}$ was seen in cases of static and shaken washing. Figure 3 showed that elements such as $\mathrm{Ca}, \mathrm{Mg}, \mathrm{K}$, and $\mathrm{Na}$ were extracted from the wood and the concentration of the elements in the samples treated by shaking was slightly higher than those of the static sample.

\subsection{Result of Charcoal Property Analysis}

Figures 4 through 7 show the results of the properties of the charcoal produced at different carbonization temperatures. Fixed carbon content and volatile component content as a function of carbonization temperatures are shown in Figure 4. It was recognized that the trends of the three samples were almost the same, and the trends of fixed carbon content and volatile component content showed a reciprocal relationship. The changes were classified in three steps; the almost first order relationship from $300^{\circ} \mathrm{C}$ to $700^{\circ} \mathrm{C}$, first constant period from $700^{\circ} \mathrm{C}$ to $900^{\circ} \mathrm{C}$, and second constant period from $1000^{\circ} \mathrm{C}$ to $1100^{\circ} \mathrm{C}$. Ash content as a function of carbonization temperature is shown in Figure 5. Under all temperatures,

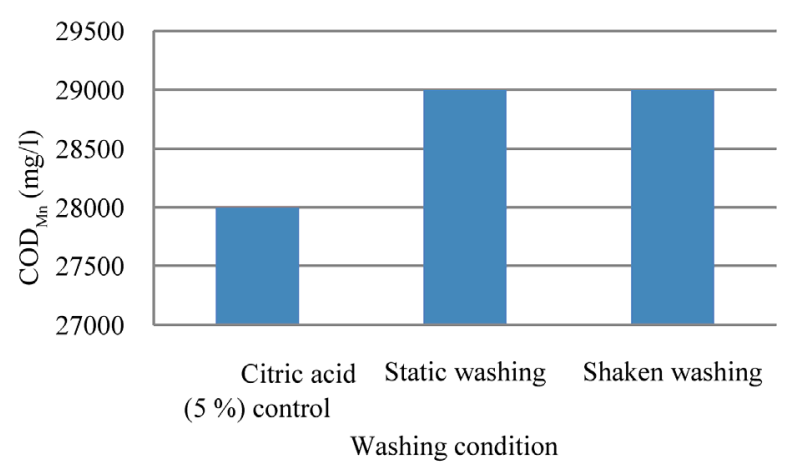

Figure 2. $\mathrm{COD}_{\mathrm{Mn}}$ of citric acid solutions after washing.

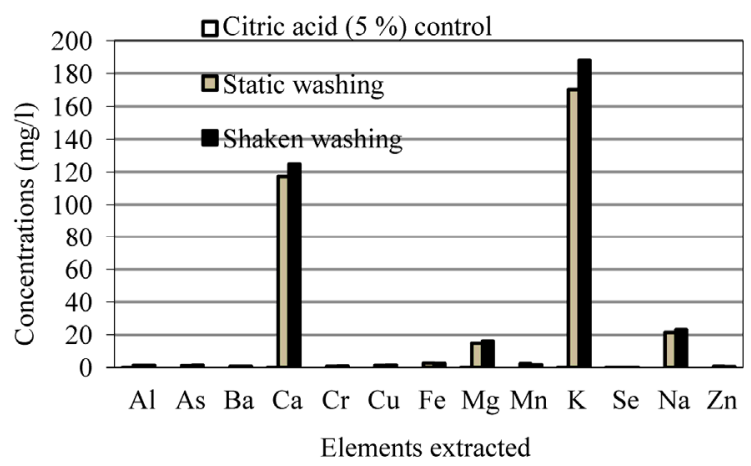

Figure 3. Impurity elements detected in citric acid solutions after washing. 


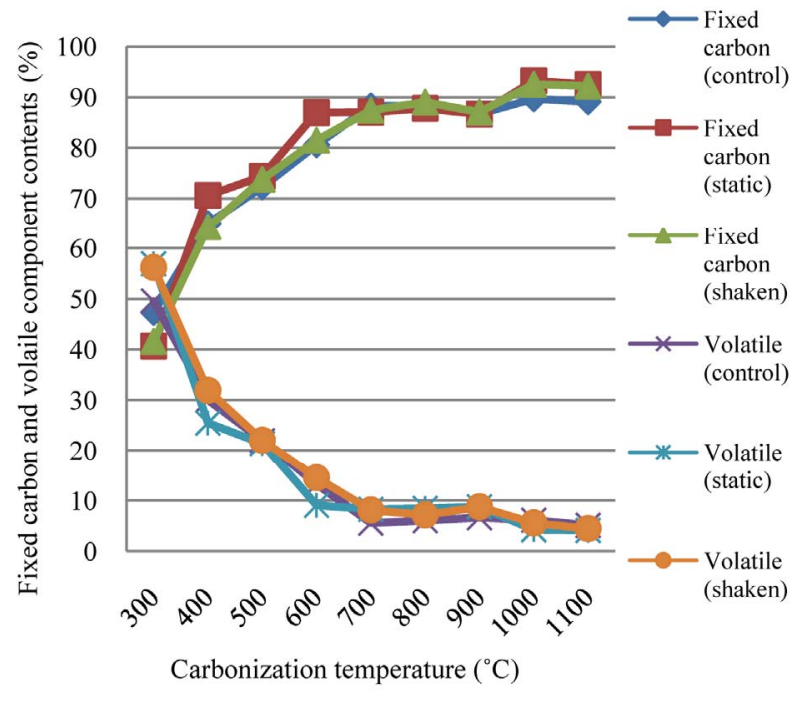

Figure 4. Fixed carbon and volatile component content as a function of carbonization temperature.

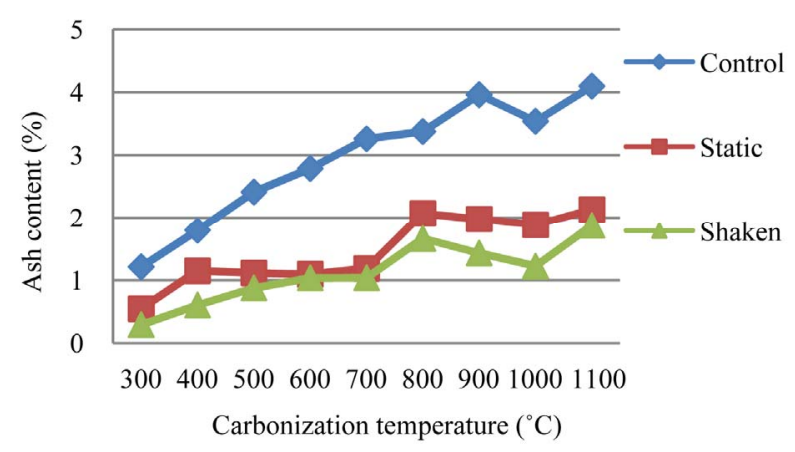

Figure 5. Ash content as a function of carbonization temperature.

ash content of the control samples was higher than the washed samples. The largest difference was shown at $700^{\circ} \mathrm{C}$. Ash content of the washed samples was about $1 \%$, whereas the control sample contained more than 3 times greater ash content than the washed ones. Among the washed samples, the static washing sample always showed a higher ash content than the shaken washing sample. The state of ash content of each sample carbonized at $500^{\circ} \mathrm{C}$ carbonization temperature is seen in Figure 8. It is obvious that the amount of ash in the control was greater than the other two samples. Water content as a function of carbonization temperature is shown in Figure 6. Water content fluctuated in a range of about $0.5 \%$ - $3.5 \%$, which is probably attributed to the experimental room condition such as room temperature and humidity. Heat values (room dry base) as a function of carbonization temperature are shown in Figure 7. Three trends were almost the same, except for the cases at $400^{\circ} \mathrm{C}$ and $600^{\circ} \mathrm{C}$ according to the figure. Heat values of the static

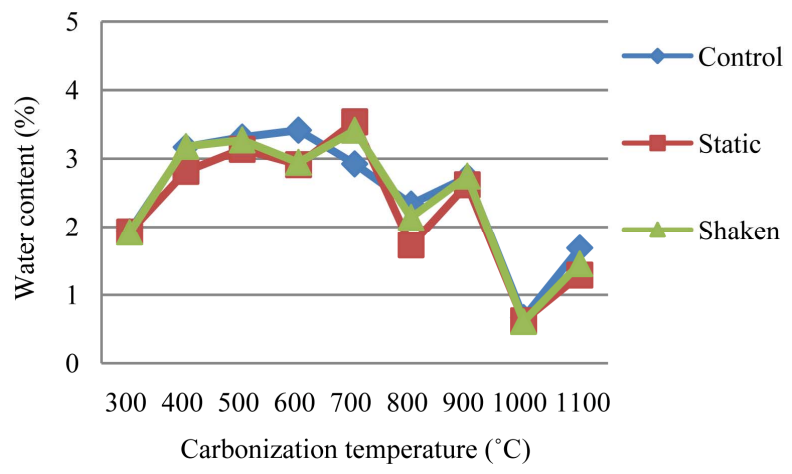

Figure 6. Water content as a function of carbonization temperature.

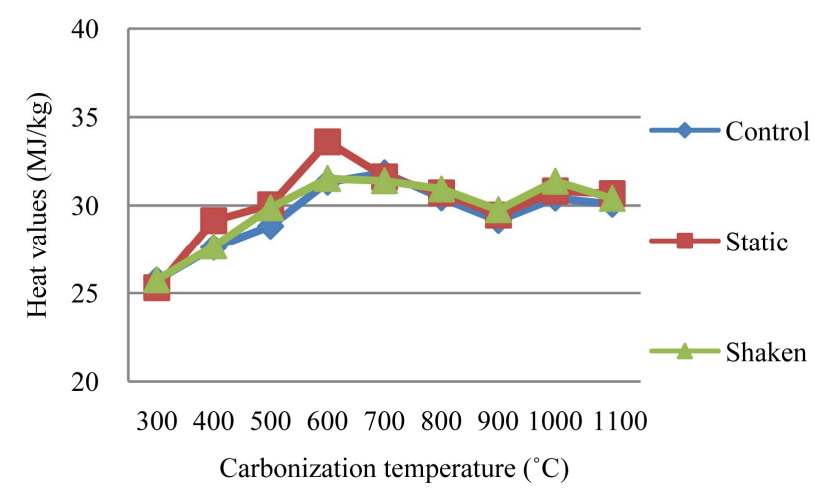

Figure 7. Heat values as a function of carbonization temperature (room dry base).

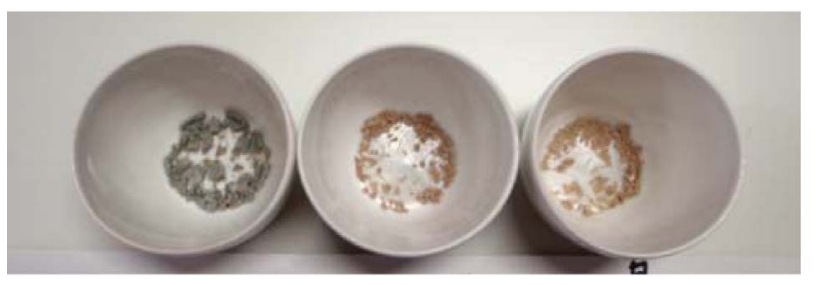

Figure 8. Ash content of the charcoal carbonized at $500^{\circ} \mathrm{C}$ Control (Left), Static (Center), Shaken (Right).

washing samples were very high at $400^{\circ} \mathrm{C}$ and $600^{\circ} \mathrm{C}$ as compared to others, and the heat value at $600^{\circ} \mathrm{C}$ became the highest in this study and was $33.6 \mathrm{MJ} / \mathrm{kg}$. Charcoal is usually grouped into 2 groups; black and white charcoals. Carbonization temperatures for black and white charcoals are $400^{\circ} \mathrm{C}-700^{\circ} \mathrm{C}$ and $800^{\circ} \mathrm{C}$ and more than $800^{\circ} \mathrm{C}$, respectively [2]. Generally speaking, black charcoal carbonized at $600^{\circ} \mathrm{C}$ shows the highest heat value of approximately $33 \mathrm{MJ} / \mathrm{kg}$ [3], which corresponds with our results.

\subsection{SEM and EDS Observations}

SEM images of charcoal carbonized at $1000^{\circ} \mathrm{C}$ shown in Figure 9. Other SEM images at $300^{\circ} \mathrm{C}, 400^{\circ} \mathrm{C}, 600^{\circ} \mathrm{C}$, 


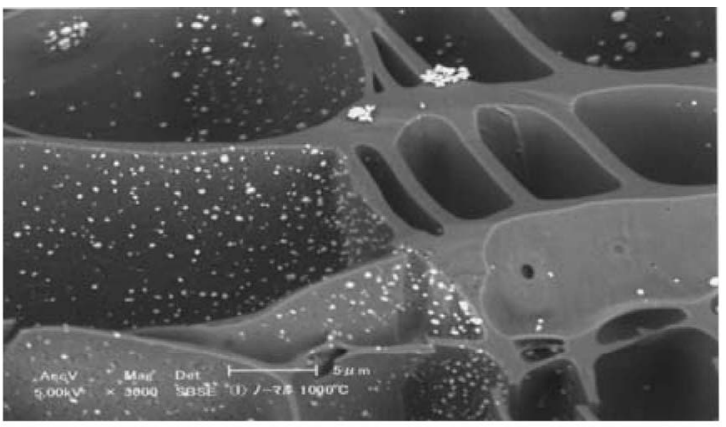

(a)

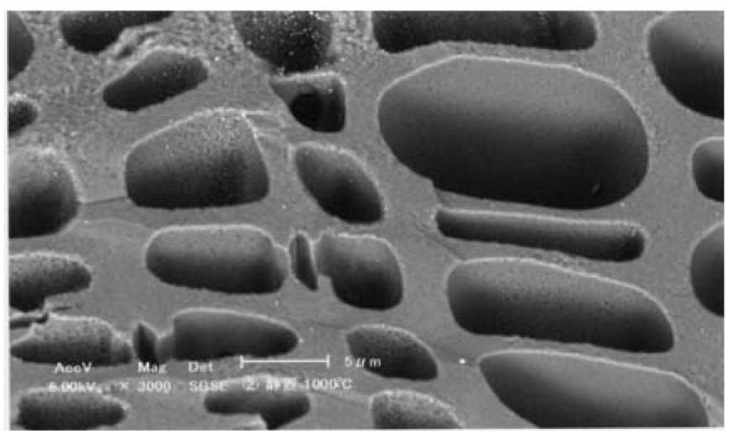

(b)

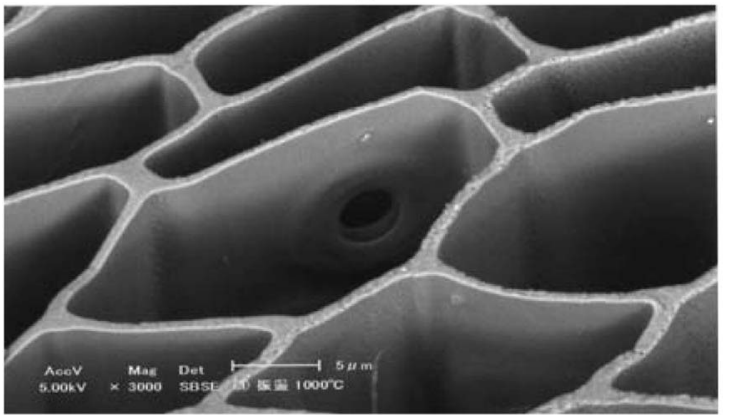

(c)

Figure 9. SEM images of the charcoals carbonized at $1000^{\circ} \mathrm{C}$ (a) Control (no washing); (b) Static washing; (c) Shaken washing.

and $700^{\circ} \mathrm{C}$ were very similar to that at $1000^{\circ} \mathrm{C}$. As shown in Figure 9(a), many white spots were observed on the surface of the holes of the charcoal without citric acid washing; whereas any spots were hardly recognized on that of the charcoal washed with citric acid by static and shaken methods (Figures 9(b) and (c)). The white spots were examined using EDS. In Figure 10, the small area was $0.5 \mu^{2}$ and the large area was $10 \mu^{2}$. According to the qualitative-quantitative analysis results in Figure 11, elements shown in figure (A) were detected in the area of $0.5 \mu^{2}$ and $\mathrm{Na}, \mathrm{Cl}$, and $\mathrm{Ti}$, as well as the elements shown in the area of $0.5 \mu \mathrm{m}^{2}$ were also detected in the area of $10 \mu \mathrm{m}^{2}$. The elements $\mathrm{C}$ and $\mathrm{O}$ that occupied a large percentage, were constituent elements of the charcoal, but other elements were impurities of the charcoal. The results shown in the figure indicate that $\mathrm{Al}, \mathrm{Si}$,

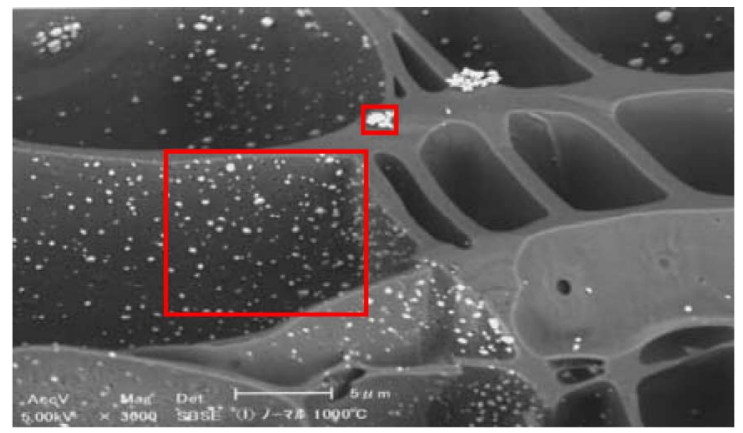

Figure 10. EDS target areas on the charcoal carbonized at $1000^{\circ} \mathrm{C}$ without washing (Control).

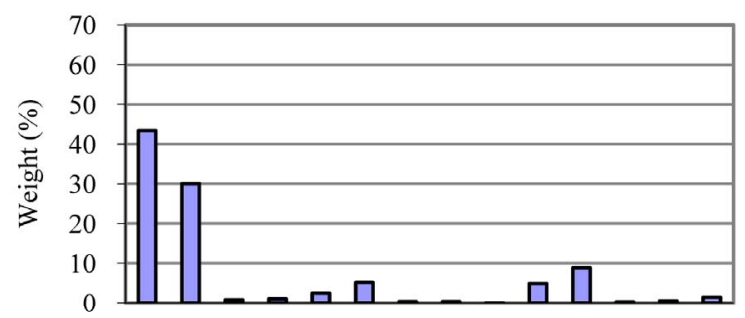

C O Na Mg Al Si P $\mathrm{S}$ Cl K Ca Ti Mn Fe

Elements detected

(a)

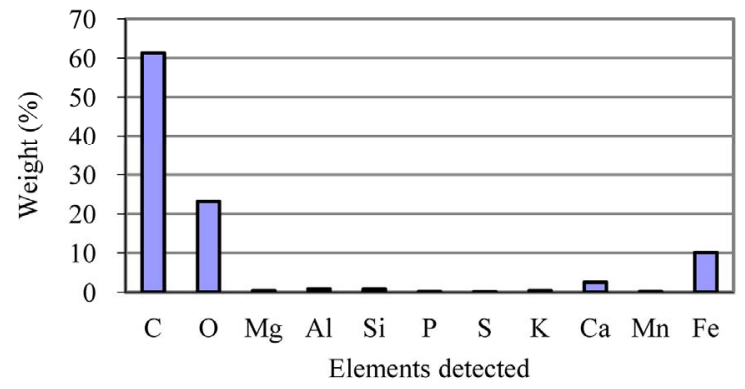

(b)

Figure 11. Qualitative-quantitative analysis of (a) 0.5 and (b) 10 micro meters squares.

$\mathrm{K}$, $\mathrm{Ca}$, and Fe were contained in a relatively large number; therefore it could be said that white spots in the areas were mainly constituted by those elements.

\subsection{Analysis of Dioxins}

Results are shown in Figure 12. Higher dioxin concentration was detected in the ashes of the charcoal with the shaken washing method for both the normal and oil and salt addition combustions. From the result, the charcoal with low levels of impurities seemed to hold dioxins in the ash.

\section{Discussion}

\subsection{Existing of Impurities on Charcoal Surface}

Impurities existing in waste construction wood and 


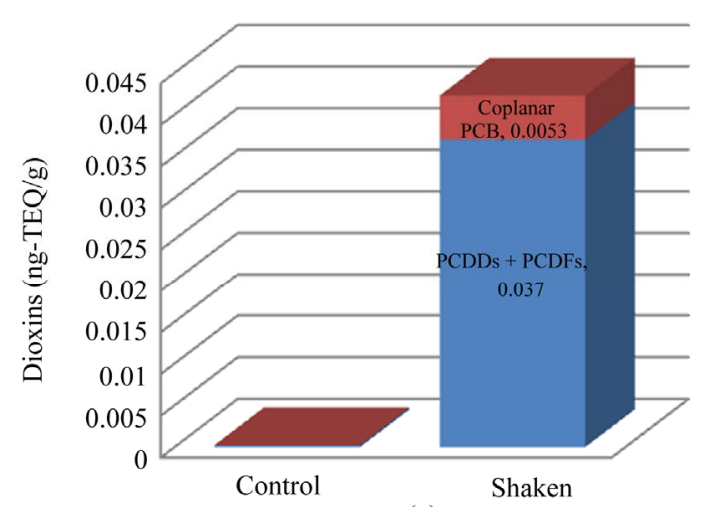

(a)

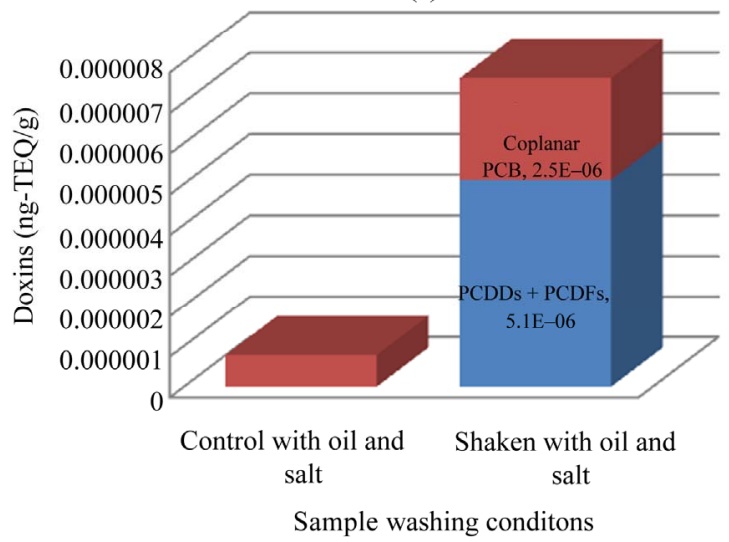

(b)

Figure 12. Dioxin concentrations in combustion ash (a) normal combustion; (b) Combustion with addition of vegetable oil and salt.

washed-out by citric acid were given in Figure 3 while, after carbonization at $1000^{\circ} \mathrm{C}$ impurities existing in charcoal are shown in Figure 11. The elements Si, P, S, Cl, and $\mathrm{Ti}$ are shown in Figure 11, but not seen in Figure 3. It was reasonable to think that those elements existed on the surface of waste construction wood, but could not be washed-out by citric acid. On the other hand, the elements $\mathrm{As}, \mathrm{Ba}, \mathrm{Cr}, \mathrm{Cu}$, Se, and $\mathrm{Zn}$ were seen in Figure 3, but not seen in Figure 11. Those elements might be originally contained at very low levels on the surface of waste construction wood supposing from Figure 3 but flew away with fly ash during carbonation at $1000^{\circ} \mathrm{C}$; therefore, those elements might not have been detected in Figure 11. Results of Figure 3 and Figure 9(b) and (c) were linked to the result of Figure 5. As also noticed visually in Figure 8, ash content in the control sample was much higher than samples with citric acid washing (Figure 5). Washing with citric acid removed impurities from the waste construction wood, so that the ash content of the sample washed by citric acid became lower than the control sample; $0.6 \%-2.1 \%$ and $0.9 \%-2.5 \%$ reduction for static and shaken washing, respectively.

\subsection{Interaction of Physical Properties of Charcoal}

Ash content for the three samples in Figure $\mathbf{5}$ increased as carbonization temperature increased. This was because of an increase of fixed carbon content with the increase of carbonization temperature. Charcoal is sometimes called amorphous carbon and crystals of the carbon are irregularly lined. The small crystals expand as carbonization temperature increases and increase fixed carbon content. Whereas, volatile component content is a volatile part in charcoal so the content decreases as carbonization temperature increases (Figure 4). The relationship between fixed carbon and volatile component content is reciprocal (Figure 13). Fixed carbon content is a form of carbon and its burnability is very low, so fixed carbon content easily remains in ash [4]. This is explained in Figure 5. High fixed carbon content indicates a state of good carbonization [4]. Heat values (absolute dry base) were given in Figure 14. Figures 7 and 14 show almost the same trends. Naturally, heat value is influenced by water, ash, volatile components, and fixed carbon content. However, in this case, it can be said that water content did not influence so much the heat values of the three samples. The trends of Figure $\mathbf{1 4}$ were ex-

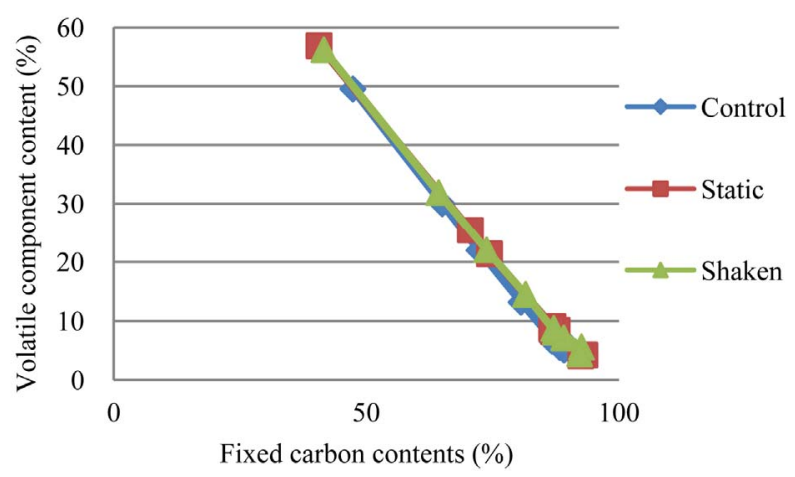

Figure 13. Fixed carbon and Volatile component content.

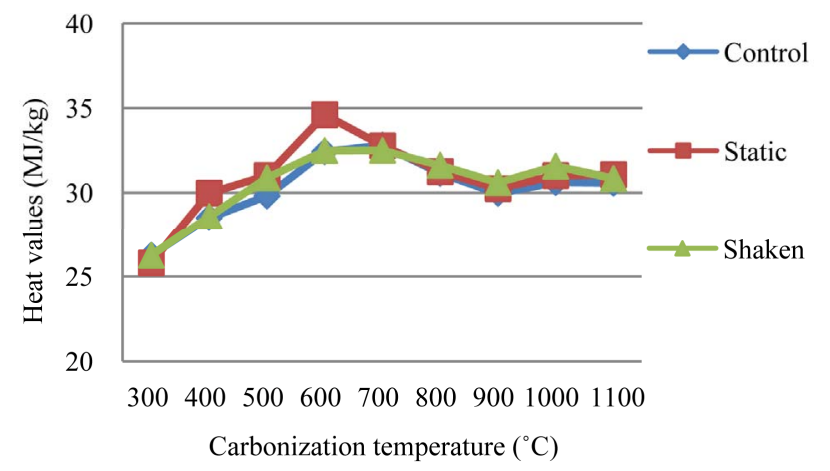

Figure 14. Heat values as a function of carbonization temperature (absolute dry base). 
amined here without considering the influence of water content. Since ash is not burnable, heat value decreases with the increase of ash. Volatile components and fixed carbon content both are burnable, although the former is quite easily burned, while fixed carbon is not easily burnable. Considering these characteristics of the content, it can be concluded that the heat value should be higher in the case of high volatile component content with low ash and fixed carbon content. Low heat value is expected in the case of low volatile component content while high in ash and fixed carbon content. The samples carbonated at $300^{\circ} \mathrm{C}$ and $1100^{\circ} \mathrm{C}$ fit the former and latter cases, respectively, according to Figures $\mathbf{4}$ and $\mathbf{5}$. So heat values of the samples at $300^{\circ} \mathrm{C}$ must be the highest, and those at $1100^{\circ} \mathrm{C}$ must be the lowest. However, Figure 14 shows totally different heat values than expected. These facts imply the following conclusions on heat values; 1) it is sure that the content of ash decreases heat value since ash is non-burnable and 2) it is not so easy to say that the heat value is low when the volatile component content is high and fixed carbon content is low and vice versa; and the interaction among water, ash, volatile component, and fixed carbon content decides the heat value of the charcoal. In this study, the static washing sample carbonated at $600^{\circ} \mathrm{C}$ showed the highest heat value. Fuel ratios of charcoal as a function of carbonization temperatures were calculated in Figure 15. The fuel ratio can be obtained by "fixed carbon content/volatile component content" and is a parameter of "tendency for burning" used for evaluation of quality of coal [4]. The fuel ratio increased with an in increase of carbonization temperature but was not related to heat value. When the sample with static washing and carbonated at $600^{\circ} \mathrm{C}$ possessed the highest heat value, the fuel ratio of the sample was 9.6.

\subsection{SEM Observation on Charcoal Structure}

Under SEM observation, all samples had a lot of holes, and porous structures of charcoal were recognized. Wood tissue structures do not change after carbonization and charcoal keeps the same structure as wood does. As features of the structure, holes are large and the walls between the holes are thin in coniferous trees and holes are small and the walls between the holes are thick in broadleaf trees. In this study, the former structure is often recognized in SEM observation, so waste construction wood obtained for this study mostly consisted of coniferous trees. Through SEM observation at each carbonization temperature, it can be noticed that porous structures at high carbonization temperatures seemed firm and tight but those at low temperatures looked loose and weak (Figure 16). Carbon crystals seemed not to form tight and solid at low carbonization temperatures. Con-

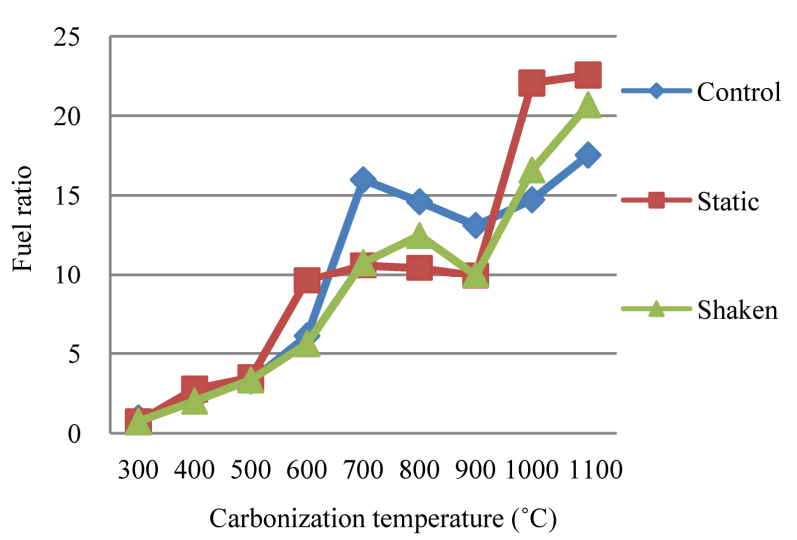

Figure 15. Fuel ratios as a function of carbonization temperature.

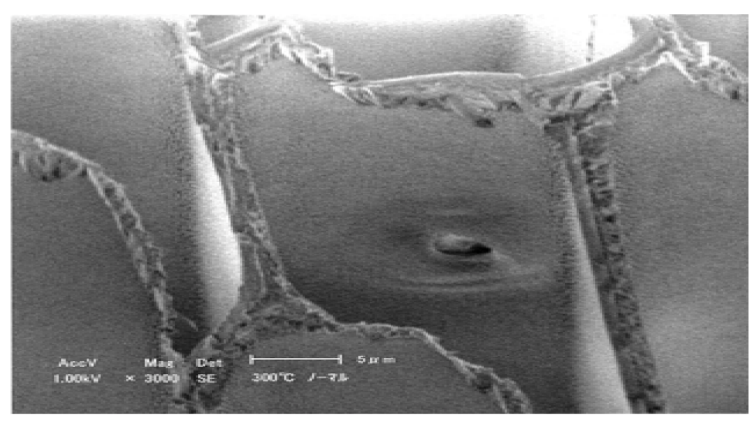

(a)

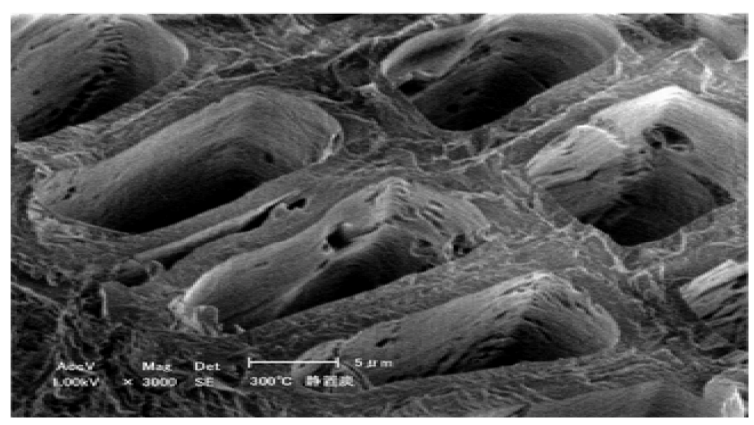

(b)

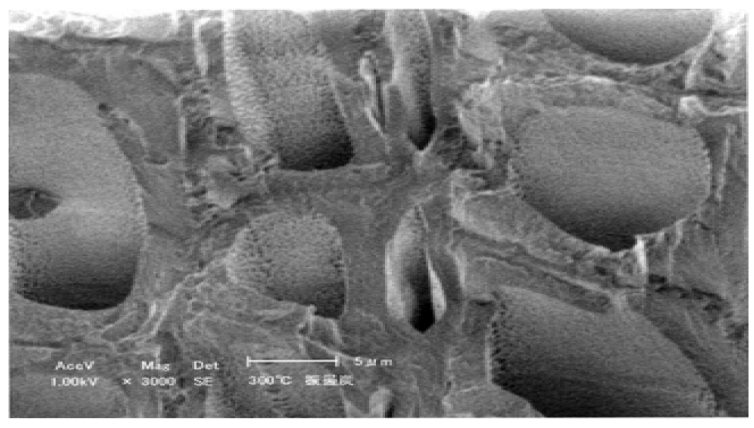

(c)

Figure 16. SEM images of the charcoals carbonized at $300^{\circ} \mathrm{C}$ (a) Control (no washing); (b) Static washing; (c) Shaken washing. 
siderable numbers of white spots were recognized on the surfaces of the charcoal without citric acid washing at each different carbonization temperature, but quality and quantity of the spots were not always similar to those shown in Figure 9; and varies by sample (data not shown). Since a variety of waste construction wood was used as sampled for this study, the construction wood originally treated with different kinds of antiseptic chemicals, glues, and coating chemicals and was dealt with differently at various demolition sites were mixed. Therefore, it should be reminded that elements shown in Figure 11 were just one example. It was easily expected that other elements on the surface of the charcoal samples existed case by case.

\subsection{Dioxin Formation in Charcoal Combustion}

It is reported that wood combustion is one of the most considerable sources for dioxin formation [5,6]. According to Elena et al (2004), a large number of waste construction wood was incinerated in open-air at the site of Hanshin-Awaji great earthquake tragedy and resulted in a large formation of dioxins in the ashes (up to $2080 \mathrm{ng}$ $\mathrm{I}-\mathrm{TEQ} / \mathrm{kg}$ ) and had six times higher level of atmospheric pollution by dioxins as compared to a normal atmospheric situation. It is reported that dioxins were formed through homogeneous (pyrolytic rearrangement of chlorinated precursors) and heterogeneous (catalyzed) reactions [7]. As catalysts, $\mathrm{Cu}$ was the main catalyst reported in many journals [6-12], and Fe [9-11], C [12] were also reported. These elements are also recognized in Figure 3 in this study. Dioxins were detected and are shown in Figure 12. According to Tateda's report [13], concentration of total PCDD (Poly Chlorinated Dibenzo-p-Dioxin) was not detected (N.D.)-110 and $5.23-10883 \mathrm{ng} / \mathrm{g}$ in bottom and fly ashes, respectively, and N.D.-65 and 3.73 - 3187 ng/g for total PCDF (Poly Chlorinated Dibenzo Furan) and N.D.-180 and N.D.-250 ng/g for total PCB (Poly Chlorinated Biphenyl). From the results above; the concentration of dioxins seemed always higher in fly ash than bottom ash, but this is not always true and depends on how it was combusted [5]. In ash generation, it was generally mentioned that fly ash was $10 \%$ of total ash after waste incineration and $90 \%$ was bottom ash [14]. In Figure 12, the samples treated with citric acid by the shaken method showed a higher concentration of dioxins than the control samples. Because of a low level of impurities in the samples treated with citric acid, it was hard to think that more dioxins were formed in fly ash. Moreover, it was also hard to find the reason that homogeneous reactions had intensively occurred in the bottom ashes of the samples treated by citric acid. Analysis of dioxins in fly ash or gases was not conducted in this study; therefore, dioxin formation in fly ash or gases is not known. The reasons that there were higher concentrations in the samples treated with citric acid shown in Figure 12 may be the following: 1) dioxins were concentrated in the bottom ashes because generation of bottom ashes was less than that of the control sample or 2) low impurity levels might keep dioxin concentration higher in bottom ashes by some mechanism such as "adsorption," which means probably low dioxin concentration in gas or fly ash. Further investigation is needed in order to clarify those assumptions.

\subsection{Use of Waste Citric Acid Solution to Composting}

As described in Figure 2, the 5\% citric acid solution had $29000 \mathrm{mg} / \mathrm{l}$ in its $\mathrm{COD}_{\mathrm{Mn}}$ after washing treatment. It is not appropriate to discharge the wastewater into the environment and should be treated or applied to other purposes. In this study, as mentioned at the beginning of this paper, the wastewater was applied to composting as a substrate. The concerning elements that destroy compost quality such as $\mathrm{As}, \mathrm{Cr}, \mathrm{Cu}, \mathrm{Mn}$, and Se were seen in Figure 2; however, those concentrations were at a very low level, so the application of the wastewater to composting was acceptable. Compost temperature was traced and is seen in Figure 17. Temperatures of compost piles with citric acid application were higher than the control pile at the beginning stage of composting. After the first turn over on April 3, temperature trends were almost the same between the control and citric acid applied piles. Citric acid is an easily degraded substance, so addition of the acid contributed to activation of microbes' metabolism at the beginning stage of composting, the most important stage in a composting operation.

\section{Conclusions}

As one of the reuse ways for wastewater containing citric acid, washing treatment of waste construction wood with citric acid solution was carried out for production of charcoal, taking advantage of citric acid's chelate bonding characteristics with elements and finding benefits of washing with citric acid in terms of charcoal production from waste construction wood. As a result, physicochemical parameters such as fixed carbon content, volatile component content, water content, and heat values were not significantly different at all carbonization temperatures between the control and citric acid treatment samples; however, significant differences were seen in ash content at all carbonization temperatures. At $700^{\circ} \mathrm{C}$ of carbonization temperature, more than 3 times were different between the control and citric acid treatment samples. The biggest problem of combustion is the ash left over. Companies and local governments that own incinerators or boilers pay a pretty high cost for ash dis- 

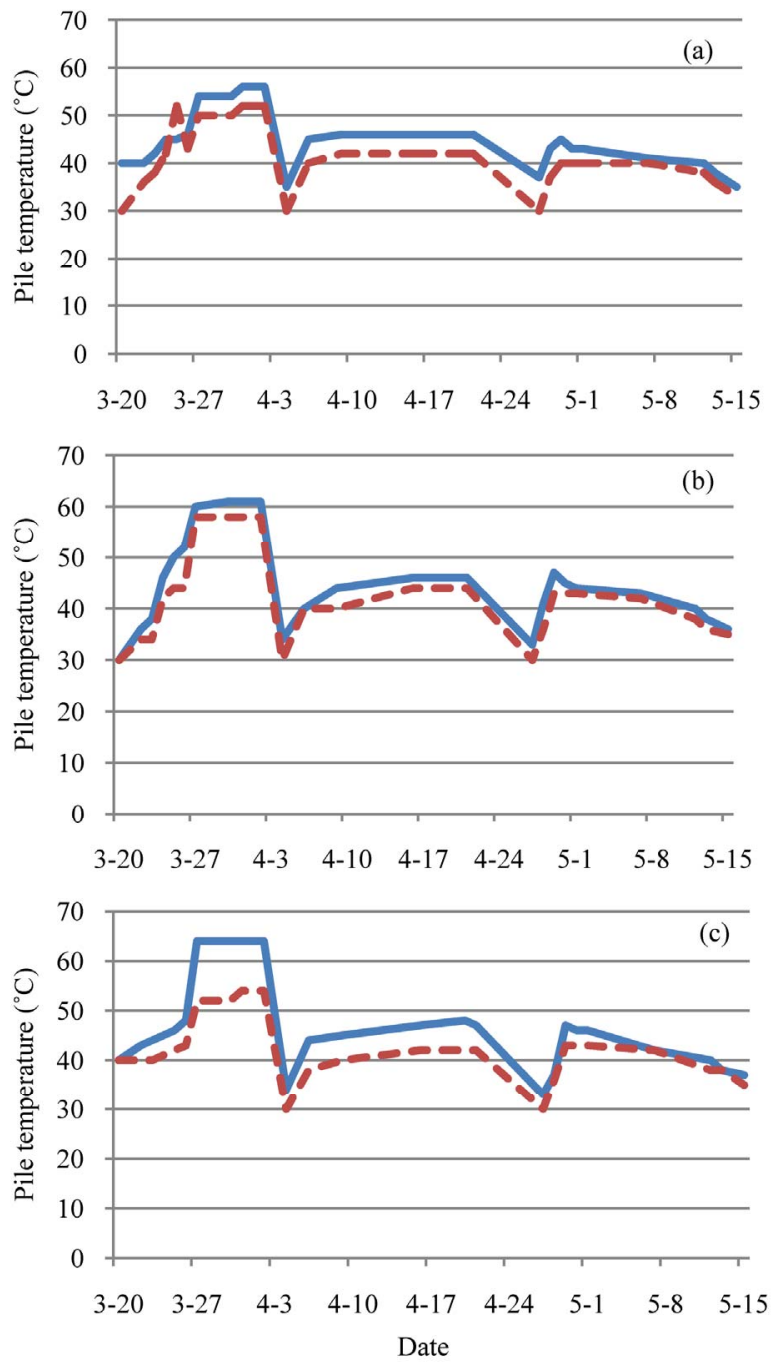

Figure 17. Comparison of compost pile temperatures (a) Normal operation; (b) 100 liter citric acid addition; (c) 200 liter citric acid addition bold line: $40 \mathrm{~cm}$ depth from pile surface, Dotted line: $80 \mathrm{~cm}$ depth from pile surface.

posal. From the result, it can be said that the amount of ash left over decreases if waste construction wood is incinerated after it is washed with citric acid wastewater. In Japan, the use of charcoal as a fuel is very limited such as in barbecue occasions with friends, specialized shops for grilled meats on a stick, Japanese style bars, and grilled meat shops. Basic data for production of high-quality charcoal was the practical purpose of this study. The production conditions of the charcoal with the highest heat value and the lowest ash generation were cleared here, but the condition of the production of the charcoal with the lowest dioxins generation could not be found in this study. Further study should focus on the generation of dioxins in charcoal combustion for production of a more safe and healthy charcoal in order to pro- duce the outstanding charcoal with its high quality under the current saturated charcoal commercial market in Japan.

\section{REFERENCES}

[1] Japan Federation Construction Contractors, "Construction Handbook,” 2010, p. 24.

[2] , "Difference between Black and White Charcoals,". http://www.kishu-binchotan.jp/mame/page3.html

[3] , "Charcoal Characteristics Given by Combustion Temperature Differences,”.

http://www.shiratori.com/jyuutaku/osusume/sumisetsu1.h tml

[4] M. Hisao, "Features and Characteristics of Coal, Chapter 1, Denchuken Review,” Central Research Institute Electric Power Industry, No. 46, 2002.

http://criepi.denken.or.jp/research/review/No46/chap-1.p df

[5] E. D. Lavric, A. A. Konnov and J. De Ruyck, "Dioxin Levels in Wood Combustion-A Review," Biomass and Bioenergy, Vol. 26, No. 2, 2004, pp. 115-145. doi:10.1016/S0961-9534(03)00104-1

[6] E. D. Lavric, A. A. Konnov and J. De Ruyck, "Modeling the Formation of Precursors of Dioxins during Combustion of Woody Fuel Volatiles,” Fuel, Vol. 84, No. 4, 2005, pp. 323-334. doi:10.1016/j.fuel.2004.09.012

[7] B. R. Stannmore, "The Formation of Dioxins in Combustion Systems,” Combustion and Flame, Vol. 136, No. 3, 2004, pp. 398-427. doi:10.1016/j.combustflame.2003.11.004

[8] T. Nakao, O. Aozasa, S. Ohta and H. Miyata, “Formation of Toxic Chemicals Including Dioxin-Related Compounds by Combustion from a Small Home Waste Incinerator,” Chemosphere, Vol. 62, No. 3, 2006, pp. 459-468. doi:10.1016/j.chemosphere.2005.04.060

[9] N. W. Tame, B. Z. Dlugogorski and E. M. Kennedy, "Formation of Dioxins and Furans during Combustion of Treated Wood," Progress in Energy and Combustion Science, Vol. 33, No. 4, 2007, pp. 384-408. doi:10.1016/j.pecs.2007.01.001

[10] D. J. Lisk, "Environmental Implications of Incineration of Municipal Solid Waste and Ash Disposal," The Science of the Total Environment, Vol. 74, No. 1, 1988, pp. 39-66. doi:10.1016/0048-9697(88)90128-3

[11] F. Tsutomu, "Waste Processing and Resource Recovery Engineering,” Kyoritsu Shuppan, Tokyo, 1998, p. 457.

[12] S. Masanobu, "Incineration Technology of Waste,” Ohmsha, Tokyo, 1995, p. 83.

[13] T. Masafumi, "Heavy Metals Bioleaching from General Waste Incineration Fly Ash," Water Purification and Liquid Wastes Treatment, Vol. 44, No. 3, 2003, pp. 111116.

[14] Japan Waste Research Foundation, "Specially Controlled General Waste Management Manual: Fly Ash,” The Chemical Daily, Tokyo, 1993, p. 7. 